\title{
RANCANG BANGUN SISTEM INFORMASI KEPEGAWAIAN BERBASIS JAVA STUDI KASUS KANTOR KELURAHAN BUARAN INDAH
}

\author{
Desi Nurnaningsih ${ }^{1}$,Angger Aifadnan ${ }^{2}$ \\ Program Studi Teknik Informatika \\ Fakultas Teknik Universitas Muhammadiyah Tangerang \\ Jl. Perintis Kemerdekaan 1/33 Cikokol Kota Tangerang \\ Email desi.nurnaningsih@umt.ac.id ${ }^{1}$, email angger.aifadnan@umt.ac.id ${ }^{2}$
}

\begin{abstract}
Buaran Indah urban village office located in Tangerang district, Tangerang City. Personnel data processing system that is running at Buaran Indah village office has not been computerized. This has an impact on data retrieval process which takes longer time. So to overcome this it is necessary information system personnel who can overcome the existing problems in order to present personnel information quickly and accurately. This research uses prototype method and system design is implemented with Unified Modeling Language (UML). The expected final result is that the proposed personnel information system can overcome the existing problems on the current system, including more leverage in the process of data processing employees and payroll calculations that require a high level of accuracy and ease in preparing reports and search personnel data. With this research is expected to help Buaran Indah village office to manage personnel data.
\end{abstract}

Keywords: Implementation, Personnel, UML Diagram, Prototype, computerization.

\section{PENDAHULUAN}

Penerapan sistem kepegawaian dalam suatu perusahaan atau instansi, baik yang dikelola pemerintah maupun swasta dapat membantu manajemen dalam mengelola aktifitas kepegawaian. Sistem informasi kepegawaian akan membantu manajemen perusahaan atau instansi dalam meningkatkan pengendalian internal kepegawaian sehingga perusahaan atau instansi dapat mencapai tujuan yang telah ditetapkan.

Pada kenyataannya, meskipun telah banyak instansi atau perusahaan yang telah menerapkan sistem kepegawaian yang terkomputerisasi seiring dengan kemajuan teknologi dan informasi, belum semua instansi menerapkannya dalam menjalankan operasionalnya. Hal tersebut terjadi pada kantor kelurahan Buaran Indah yang selama ini masih menerapkan sistem kepegawaian secara manual.

Kelemahan penerapan sistem kepegawaian manual seperti yang diterapkan di kantor kelurahan Buaran Indah, berdampak pada tingkat keakuratan data. Sistem kepegawaian manual mengandalkan tenaga manusia sehingga sangat dimungkinkan terjadinya kesalahankesalahan dalam proses pengolahan data kepegawaian. Salah satu kelemahan yang dijumpai dengan penerapan sistem kepegawaian manual seperti yang diterapkan di kantor kelurahan Buaran Indah adalah penyimpanan data yang kurang terjamin.

Sistem kepegawaian manual memiliki kelemahan yakni dimungkinkannya data pegawai hilang atau terselip di berkas-berkas lainnya yang sering menumpuk. Kehilangan data pegawai dapat menyulitkan bagian 
keuangan untuk melakukan pengendalian atau kontrol terhadap pengelolaan data pegawai.

Penerapan sistem kepegawaian manual yang ada di kantor kelurahan Buaran Indah juga memiliki keterbatasan dalam pengerjaan. Sistem kepegawaian manual membutuhkan waktu yang relatif lebih lama. Hal ini dikarenakan hanya mengandalkan tenaga manusia. Apabila sumber daya manusianya mengalami keterbatasan kemampuan maka akan dibutuhkan waktu yang lebih lama. Selain itu, keterbatasan sistem kepegawaian manual juga berdampak pada pembuatan laporanlaporan mengenai cuti dan penggajian pegawai. Sistem kepegawaian manual memiliki keterbatasan bahwa data tidak terkontrol secara berkelanjutan dari waktu ke waktu, hilangnya sebagian data sehingga akan kesulitan dalam membuat laporan yang baik mengenai cuti dan penggaji pegawai.

\section{TINJAUAN PUSTAKA}

\section{A. Rancang Bangun}

Menurut Jogiyanto (2005:197), Rancang Bangun adalah tahap dari setelah analisis dari siklus pengembangan sistem yang merupakan pendefinisian dari kebutuhan-kebutuhan fungsional serta menggambarkan bagaimana suatu sistem dibentuk yang dapat berupa penggambaran, perencanaan dan pembuatan sketsa atau pengaturan dari beberapa elemen yang terpisah kedalam satu kesatuan yang utuh dan berfungsi, termasuk menyangkut konfigurasi dari komponen-komponen perangkat keras dan perangkat lunak dari suatu sistem.

\section{B. Sistem Informasi}

Menurut Ais Zakiyudin (2011:9) "Sistem Informasi adalah suatu sistem yang ada di dalam suatu organisasi yang mempertemukan kebutuhan pengolahan transaksi harian, mendukung operasi yang bersifat manajerial dan kegiatan strategi dari suatu organisasi dan pihak user tertentu dengan laporan yang diperlukan"

Menurut Krismiaji (2010:4) mendefinisikan "Sistem Informasi adalah sebuah sistem yang memproses data dan transaksi guna menghasilkan informasi yang bermanfaat untuk merencanakan, mengendalikan, dan mengoprasikan bisnis".

\section{Komponen Sistem Informasi}

Menurut Mulyanto (2009:31) "Sistem informasi terdiri dari lima sumber daya yang di kenal sebagai komponen sistem informasi, kelima sumberdaya tersebut adalah, manusia, hardware, software, data dan jaringan". Kelima komponen ini memainkan peranan yang sangat penting dalam sistem informasi. Namun dalam kenyataannya tidak semua sistem informasi mencakup lima komponen tersebut misalnya, sistem informasi pribadi yang mencakup jaringan telekomunikasi.

1. Sumber daya manusia

Manusia mengambil peranan yang penting bagi sistem informasi. Manusia dibutuhkan untuk mengoperasikan sistem informasi. Sumber daya manusia dapat dibedakan menjadi dua kelompok yaitu pengguna akhir (end user) dan pakar sistem informasi. Pengguna akhir (end user) adalah orangorang yang menggunakan informasi yang dihasilkan dari sistem informasi, misalnya pelanggan, pemasok, teknisi, mahasiswa, dosen, dan orang-orang yang berkepentingan dengan informasi dari sistem informasi tersebut. Sedangkan pakar sistem informasi adalah orang-orang yang mengembangkan dan mengoperasikan sistem informasi, misalnya sistem analis, developer, operator sistem, dan staf administrasi lainnya.

2. Sumber daya hardware

Sumber daya hardware adalah semua peralatan yang digunakan dalam pemrosesan informasi. Sumber daya hardware tidak hanya sebatas komputer saja, melainkan semua media data seperti lembaran kertas dan disc magnetic atau optical.

3. Sumber daya software

Sumber daya software adalah semua rangkaian perintah (instruksi) yang digunakan untuk memproses informasi. Sumber daya software tidak hanya berupa program saja, tetapi juga berupa prosedur. Program merupakan sekumpulan instruksi untuk memproses informasi. Sedangkan 
prosedur adalah sekumpulan aturan yang digunakan untuk mewujudkan pemrosesan informasi dan mengoperasikan perintah bagi orang-orang yang akan menggunakan informasi.

4. Sumber daya data

Sumber daya data bukan hanya sekedar bahan baku untuk masukan sebuah sistem informasi, melainkan sebagai dasar membentuk sumber daya organisasi. Seperti yang dijelaskan sebelumnya data dapat berbentuk teks, gambar, audio, maupun video.

5. Sumber daya jaringan

Sumber daya jaringan merupakan media komunikasi yang menghubungkan komputer, pemroses komunikasi, dan peralatan lainnya, serta dikendalikan melalui software.

\section{Rekayasa Perangkat Lunak}

1. Pengertian Perangkat Lunak

Menurut M. Shalahuddin (2014:2), yang di maksud dengan perangkat lunak adalah program komputer yang terasosiasi dengan dokumentasi perangkat lunak seperti dokumentasi kebutuhan, model desain, dan cara penggunaan".

2. Pengertian Rekayasa Perangkat Lunak

Definisi rekayasa perangkat lunak menurut M. Shalahuddin (2014:4) adalah pembangunan dengan menggunakan prinsip atau konsep rekayasa dengan tujuan menghasilkan perangkat lunak yang bernilai ekonomi yang dipercaya dan bekerja secara efisien menggunakan mesin".

\section{E. SDLC}

Menurut M. Shalahuddin dan Rosa A.S (2014:26), SDLC atau sering juga disebut Software Development Life Cycle atau sering disebut juga System Development Life Cycle adalah proses mengembangkan atau mengubah suatu sistem perangkat lunak dengan menggunakan model-model dan metodologi yang digunakan orang untuk mengembangkan sistem-sistem perangkat lunak sebelumnya. Tahapan-tahapan yang ada pada SDLC secara global adalah sebagai berikut:
1. Inisiasi (Initiation)

Tahap ini biasanya ditandai dengan proposal pembuatan proyek perangkat lunak.

2. Pengembangan Konsep Sistem (system concept develompment)

Mendefinisikan lingkup konsep termasuk dokumen lingkup sistem, analisis manfaat biaya, manajemen rencana, pembelajaran sistem.

3. Perencanaan (Planning)

Mengembangkan rencana manaemen proyek dan dokumen perencnaan lainnya. Menyediakan dasar untuk mendapatkan sumber daya (resources) yang dibutuhkan untuk memperoleh solusi.

4. Analisis Kebutuhan (requirements analysis)

Menganalisis kebutuhan pemakai sistem perangkat lunak (user) dan mengembangkan kebutuhan user. Membuat dokumentasi kebutuhan fungsional.

5. Desain (design)

Mentransformasikan kebutuhan detail menjadi kebutuhan yang sudah lengkap, dokumen desain sistem fokus pada bagaimana dapat memenuhi fungsisungsi yang dibutuhkan.

6. Pengembangan (development)

Mengonversi desain ke sistem informasi yang lengkap termasuk bagaimana memperoleh dan melakukan instalasi lingkungan sistem yang dibutuhkan; membuat basis data dan mempersiapkan prosedur kasus pengujian; mempersiapkan berkas atau file pengujian, pengodean, pengompilasian, memperbaiki dan membersihkan program; peninjauan pengujian.

7. Integrasi dan Pengujian (integration and test)

Mendemonstrasikan sistem perangkat lunak bahwa telah memenuhi kebutuhan yang dispesifikasikan pada dokumen kebutuhan fungsional. Dengan diarahkan oleh staf penjamin kualitas (quality assurance) dan user. 
Menghasilkan laporan analisis pengujian.

\section{METODOLOGI PENELITIAN}

\section{A. Objek Penelitian}

Dalam penyusunan skripsi ini penulis melakukan penelitian dengan mengambil objek penelitian pada Kantor Kelurahan Buaran Indah, di Jl. Prof. Dr. Soepomo, Kelurahan Buaran Indah, Kecamatan Tangerang, Kota Tangerang, 15119. Adapun penelitian ini dilakukan untuk mengetahui seberapa besar pengaruhnya terhadap sistem kepegawaian pada Kantor Kelurahan Buaran Indah.

\section{B. Metode Pengumpulan Data}

1. Studi Pustaka

Studi pustaka dilakukan dengan melakukan pencarian terhadap buku-buku yang berhubungan dengan penelitian, karya-karya ilmiah maupun jurnal, baik yang terdapat diperpustakaan maupun yang terdapat di internet, yang dijadikan referensi dalam penyusunan skripsi ini sehingga data-data yang disajikan dapat dipertanggung jawabkan.

2. Observasi

Tahap ini merupakan tahap pengamatan menyeluruh terhadap sistem yang sedang berjalan di kantor kelurahan Buaran Indah. Kemudian mempelajari kekurangankekurangan yang ada, setelah itu diambil kesimpulan sementara mengenai masalahmasalah yang ada secara menyeluruh dan mendefinisikan masalah tersebut.

3. Wawancara

Wawancara dilakukan dengan cara mewawancarai langsung pihak-pihak terkait, yang berguna untuk mendapatkan informasi maupun data-data yang dibutuhkan untuk perancangan sistem yang akan dibangun.

\section{HASIL DAN PEMBAHASAN} A. Gambaran Umum Sistem yang diusulkan

Perancangan sistem dilakukan untuk memberikan gambaran umum tentang sistem yang dikembangkan atau yang dirubah menjadi sistem yang baru kepada pemakai atau user. Tahapan desain sistem mempunyai 2 maksud dan tujuan utama yaitu:

1. Untuk memenuhi kebutuhan kepada pemakai sistem.

2. Untuk memberikan gambaran yang jelas dan rancang bangun yang lengkap kepada programmer.

Tujuan kedua lebih mengarah pada desain sistem yang terinci yaitu pembuatan rancang bangun yang jelas dan lengkap yang nantinya digambarkan untuk pembuatan program aplikasi.

Dalam perancangan sistem yang akan dibuat terdapat tahapan-tahapan yang dilakukan agar dalam pembuatan sistem yang baru lebih terarah dan lebih terurut, sehingga apabila sistem yang telah jadi dan ada kesalahan dapat ditemukan dan diperbaiki dengan mudah.

Tahapan selanjutnya setelah proses analisa sistem yang berjalan adalah proses analisa sistem yang diusulkan, dengan analisis sistem yang ada bahwa sistem lama kurang mampu memenuhi kebutuhan dalam memperoleh data dan laporan dengan cepat, perolehan informasi yang sesuai dengan kebutuhan sistem, dalam proses analisa sistem ini penulis menggolongkan pengguna sistem menjadi beberapa bagian level bagian diantaranya:

1. Administrator

Seorang user yang bisa melakukan input data dengan cara melakukan login terlebih dahulu dan mempunyai akses masuk ke sistem sebagai administrator pengelola system. Administrator memiliki beberapa fungsi sistem yaitu:

a. Tambah User (Pengguna Aplikasi).

b. Melihat seluruh data. 
c. Mencetak semua laporan.

d. Reset data (mengubah data).

2. Lurah

Lurah adalah seorang aktor atau pengguna sistem informasi kepegawaian yang diberikan hanya melihat dan mencetak seluruh laporan. Lurah memiliki beberapa fungsi sistem sebagai berikut:

a. Melihat seluruh data.

b. Cetak seluruh laporan.

\section{B. Perancangan Use Case Diagram}

Use Case Diagram digunakan untuk menjelaskan apa yang akan dilakukan oleh sistem serta aktor-aktor yang akan berhubungan dengan proses-proses yang ada di sistem yang di usulkan.

Diagram use case memperlihatkan hubungan-hubungan yang terjadi antara aktor-aktor dengan use case-use case dalam sistem pada use case ini penulis memberikan gambaran mengenai aktor yang terdapat didalam sistem yang terbagi menjadi dua level diantaranya:

a. Level Admin.

b. Level Lurah.

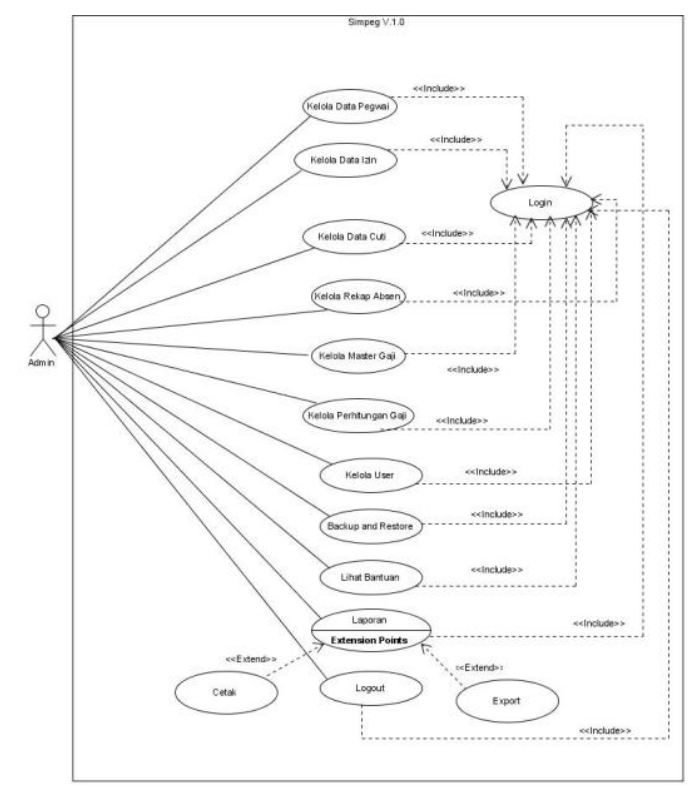

Gambar 4.1. Use Case Diagram Admin

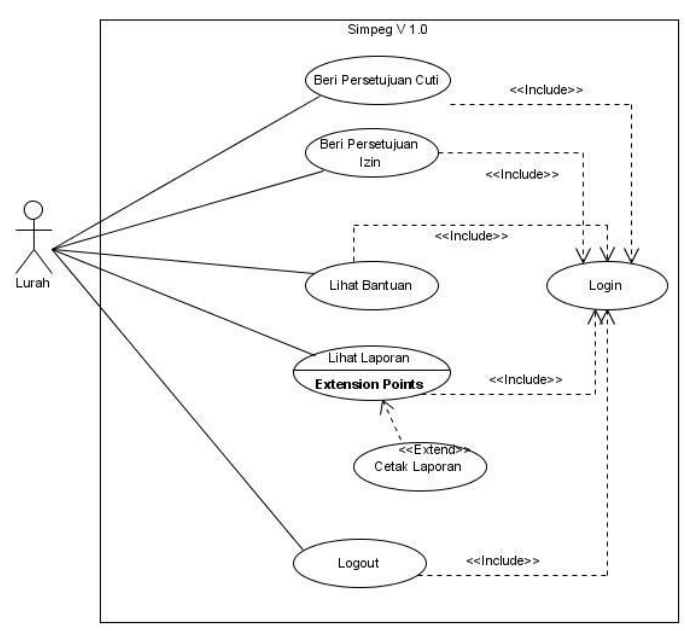

Gambar 4.2. Use Case Diagram Lurah

\section{Perancangan Antarmuka Sistem}

Tujuan utama dari perancangan antarmuka adalah agar interface yang terbentuk bersifat komunikatif dan mudah digunakan oleh pemakai sehingga tujuan dari pembuatan aplikasi tercapai.

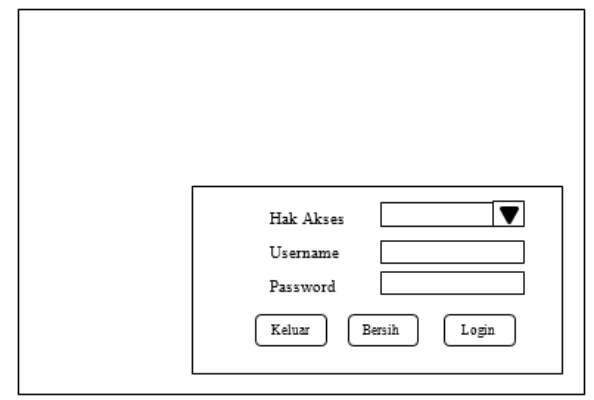

Gambar 4.3. Tampilan Login

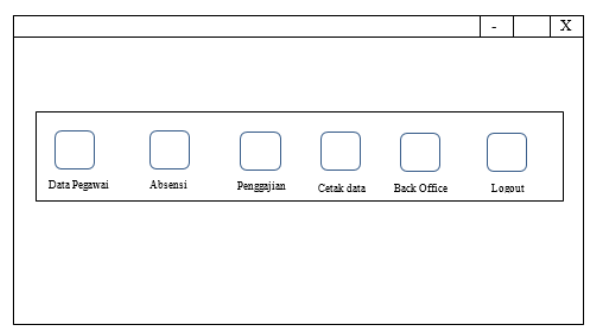

Gambar 4.4. Tampilan Menu Utama 


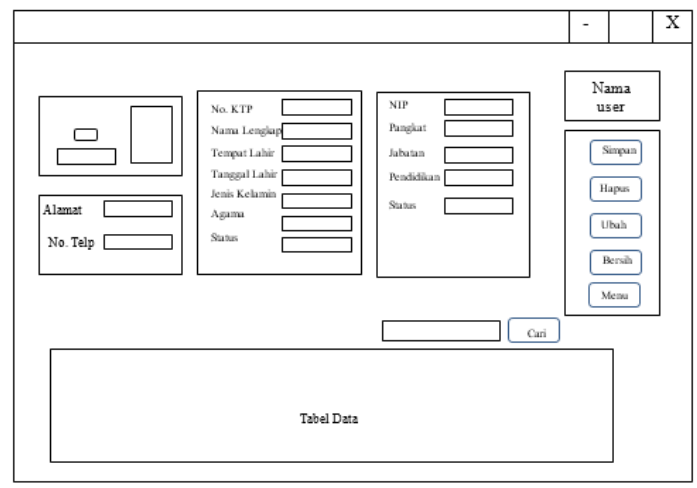

Gambar 4.5. Tampilan Form Data Pegawai

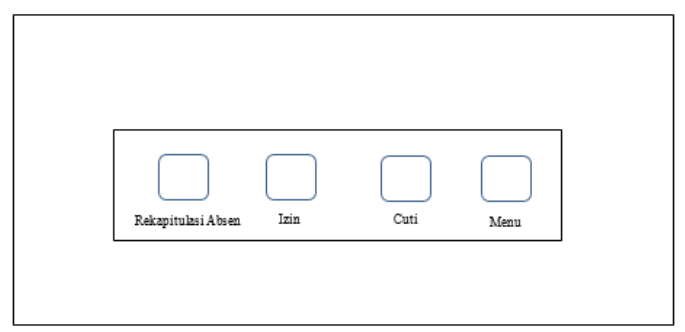

Gambar 4.6. Tampilan Menu Absensi

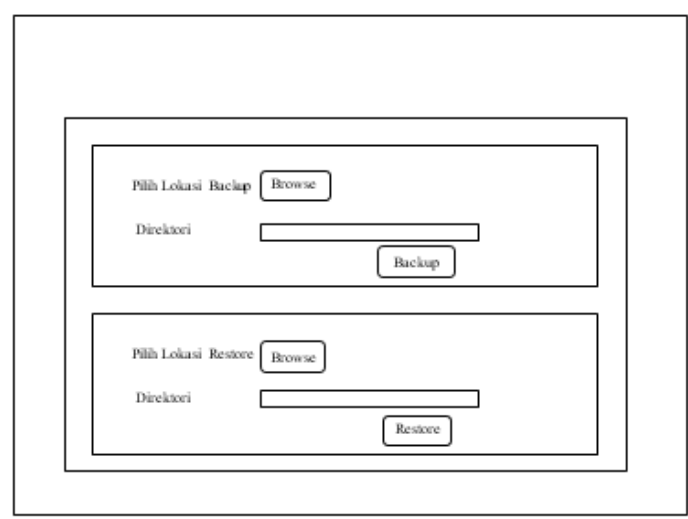

Gambar 4.7. Tampilan Form Backup and Restore

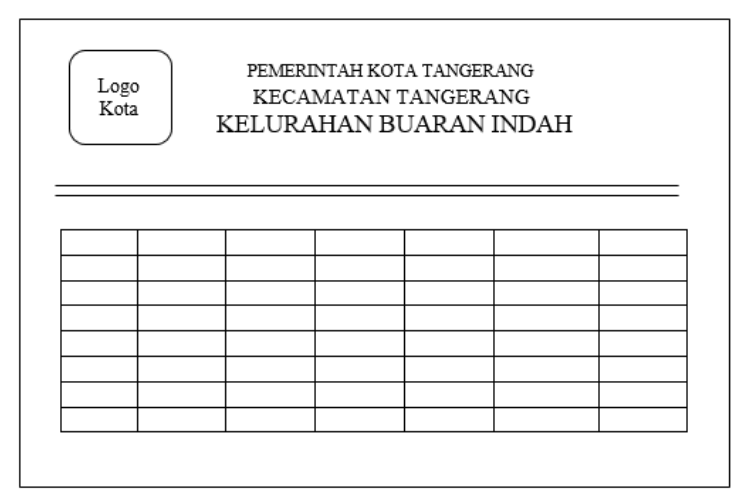

Gambar 4.8. Tampilan laporan semua data pegawai

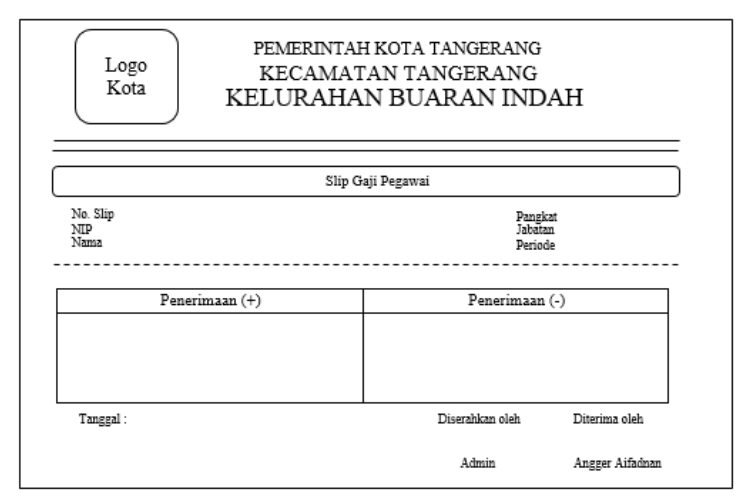

Gambar 4.9. Tampilan Slip Gaji Pegawai

\section{KESIMPULAN}

Dengan dibangunnya Sistem Informasi kepegawaian dapat menangani masalah bagi instansi terkait dalam hal ini kantor kelurahan Buaran Indah. Sistem informasi kepegawaian yang diusulkan dibuat dengan model prototype agar pihak kantor kelurahan Buaran Indah dapat menspesifikasikan kebutuhan sistem secara lebih detail. Kemudian dibuat antarmuka Backup and Restore untuk mencadangkan dan memulihkan database, serta tombol export untuk menyalin data ke dalam file Microsoft Excel. Hal ini dirasa perlu untuk mengantisipasi hilangnya data yang diakibatkan oleh human error. Dan rumusrumus perhitungan disisipkan kedalam algoritma coding program untuk mengotomatisasikan perhitungan-perhitungan yang membutuhkan tingkat keakuratan yang tinggi, serta dibuat algoritma program yang 
dapat mempercepat proses pencarian dan pengolahan data.

\section{REFERENSI}

[1] Jogiyanto, 2005, Analisis dan Desain. Yogyakarta, Andi.

[2] Krismiaji, 2010, Sistem Informasi Akuntansi. Yogyakarta, UPP AMP YKPN.

[3] Mulyanto, Agus, 2009, Sistem Informasi Konsep dan Aplikasi. Yogyakarta, Pustaka Belajar.

[4] Rosa, A.S dan M. Shalahuddin, 2014, Rekayasa Perangkat Lunak Terstruktur dan Berorientasi Objek. Bandung. Informatika.

[5] Zakiyudin, Ais, 2011, Sistem Informasi Manajemen. Jakarta, Mitra Wacana Media. 